\title{
Thoughts on Natal Dispersal
}

Author(s): Vincenzo Penteriani and MarÍadel Mar Delgado

Source: Journal of Raptor Research, 43(2):90-98. 2009.

Published By: The Raptor Research Foundation

DOI: http://dx.doi.org/10.3356/JRR-08-39.1

URL: http://www.bioone.org/doi/full/10.3356/JRR-08-39.1

BioOne (www.bioone.org) is a nonprofit, online aggregation of core research in the biological, ecological, and environmental sciences. BioOne provides a sustainable online platform for over 170 journals and books published by nonprofit societies, associations, museums, institutions, and presses.

Your use of this PDF, the BioOne Web site, and all posted and associated content indicates your acceptance of BioOne's Terms of Use, available at www.bioone.org/ page/terms_of use.

Usage of BioOne content is strictly limited to personal, educational, and noncommercial use. Commercial inquiries or rights and permissions requests should be directed to the individual publisher as copyright holder. 


\title{
THOUGHTS ON NATAL DISPERSAL
}

\author{
VINCENZO PENTERIANI ${ }^{1}$ \\ Department of Conservation Biology, Estación Biológica de Doñana, C.S.I.C., c/Americo Vespucio s/n, \\ 41092 Seville, Spain
}

\author{
MARÍA Del MAR Delgado \\ Department of Conservation Biology, Estación Biológica de Doñana, C.S.I.C., c/Americo Vespucio s/n, \\ 41092 Seville, Spain \\ Laboratory of Ecological and Evolutionary Dynamics, Department of Biological and Environmental Sciences, \\ University of Helsinki, FI-00014 Helsinki, Finland
}

\begin{abstract}
Natal dispersal (i.e., movement of wandering individuals from their birthplaces to their first breeding locations) is one of the most important yet least understood features of ecology, population biology, and evolution. The analysis of the dispersal process from the perspective of the unusual lifehistories of raptors (typically less-studied species, because of the difficulties inherent in working with them) may enhance our understanding of some additional aspects of dispersal. Here we comment on the potential offered by studies on raptor natal dispersal, in particular: (a) the importance of floaters in the dynamics, stability, and persistence of breeding populations; (b) the complexity of dispersal as a multistep process characterized by several shifts in behavior; (c) the importance of studying patterns of animal movement, which influence the patterns of population spatial structure; (d) the crucial conservation implications of dispersal studies.
\end{abstract}

KEY WORDS: animal movement; floater, natal dispersal; settlement areas.

\section{PENSAMIENTOS SOBRE LA DISPERSIÓN NATAL}

RESUMEN.-La dispersión natal (i.e., el movimiento de los individuos desde su lugar natal hasta el lugar donde se reproducen por primera vez) es uno de los procesos más importantes pero menos entendidos en ecología, biología de poblaciones y evolución. El análisis del proceso de dispersión desde la perspectiva de las historias de vida poco usuales de las aves rapaces (generalmente son las especies menos estudiadas debido a las dificultades inherentes de trabajar con ellas) puede aumentar nuestro entendimiento sobre algunos aspectos adicionales de la dispersión. Aquí comentamos el potencial que ofrecen los estudios sobre dispersión natal en las rapaces, en particular sobre: (a) la importancia de los individuos flotantes en la dinámica, estabilidad y persistencia de las poblaciones reproductivas; (b) la complejidad de la dispersión como un proceso con múltiples etapas y caracterizado por cambios en el comportamiento; (c) la importancia de estudiar los patrones de movimiento en animales, que influyen en los patrones de estructura espacial de las poblaciones; (d) las implicancias cruciales para la conservación que tienen los estudios sobre dispersión.

[Traducción del equipo editorial]

Natal dispersal (i.e., the movement of wandering individuals from their birthplaces to their first breeding locations, hereafter "dispersal"; Greenwood 1980, Ronce 2007) can be considered one of the most intriguing ecological processes, one that has stimulated the scientific curiosity of several generations of researchers. Several recent studies on

\footnotetext{
${ }^{1}$ Email address: penteriani@ebd.csic.es
}

natal dispersal of raptors have illustrated the importance of this group of species for providing novel information on this topic at a broad ecological level (e.g., Kenward et al. 2001, Forero et al. 2002, Forsman et al. 2002, Serrano and Tella 2003, Serrano et al. 2003, Kauffman et al. 2004, Walls et al. 2005, Koopman et al. 2007, Delgado and Penteriani 2008). However, raptor studies have been mostly characterized by a descriptive approach, resulting in low-quality information on the complexity of 
the dispersal process. Dispersal can be considered an example of a common problem in ecology: the availability of some knowledge about patterns, with only limited information about the processes responsible for those patterns (Hanski and Gaggiotti 2004, Bowler and Benton 2005). As a consequence, dispersal is still one of the most important, yet least understood, features of ecology, population biology, and evolution (Wiens 2001, Baguette and Van Dyck 2007). Thus, when surveying raptor literature on natal dispersal, our overall impression is that researchers have frequently passed over the potential offered by this group of species by limiting studies to simply observation of patterns.

Here we present some personal points of view about the potential offered by raptors for natal-dispersal studies. Undoubtedly, they do not represent an exhaustive series of remarks on dispersal (due to the extreme complexity of this ecological process), but we hope they will help us to identify key topics that should be addressed to improve raptor research on the topic of natal dispersal.

The Importance of Studying Raptors. Raptors allow us to study dispersal from a new perspective, because their life histories frequently differ from those of species previously used for dispersal investigations. In a sense, the behavioral ecologist is daily confronted with the dichotomy of studying peaceful fish swimming in the aquarium of his or her office, or white sharks surrounding his or her rubber dinghy. Raptors may be more difficult to study, but they offer new and unexpected insights into ecological questions. They give us the possibility of presenting original and novel results, even when addressing biological questions that researchers have studied for decades.

For example, we may learn: (a) the costs and benefits of different dispersal strategies (e.g., waiting close to the natal population versus moving away to new areas/populations); (b) how populations with dispersing individuals ("floaters") may affect numbers in neighboring populations; (c) how conspecific density and prey availability may influence dispersal patterns and movements; and (d) the effects of poorly known dispersal strategies on applied ecology and species/habitat conservation.

Dispersal is a field that embraces a multitude of disciplines, from population ecology and genetics to conservation biology. In addition, the understanding of the dispersal process is important for empirical, theoretical, and applied ecology. The study of dispersal with respect to raptors' unusual life histo- ries has the potential to generate new, unexplored questions in all these fields. Compared to dispersal studies on other species, raptor dispersal studies that are well executed are a rarity.

Floaters, the Actors of Dispersal. The process of dispersal and dispersing individuals are crucial elements regulating dynamics, trajectories, spatial-temporal distributions, and stability of animal populations, as well as their likelihood of extinction. During the last $30 \mathrm{yr}$, the study of animal populations has shifted from a fairly simple science (based primarily on the breeding portion of populations) to a more refined discipline that explicitly recognizes that populations are composed of multiple units.

We now have the potential to further understand the complexity of population dynamics, by explicitly considering the nonbreeding portions of a population, the floaters (i.e., dispersing individuals able to enter the breeding population when a breeding territory becomes available) within demographic analyses of avian populations. Previous work has illustrated how the survival of the reproductive portions of a population is strongly dependent on the dynamics of floaters, on the number of available settlement areas (i.e., temporary settling zones used by juveniles during natal dispersal) and on the type of fluctuations between the floating and breeding portions of a population (Penteriani et al. 2005a). In addition, the availability of the main prey types influences dispersal movements among the different settlement areas (Penteriani et al. 2006a), and an increase in the mortality rate within settlement areas can dramatically affect the stability and persistence of breeders (Penteriani et al. 2005b). Finally, the patterns and dynamics that are observed in the breeding sectors of a population may have their origin in the patterns and dynamics that occur in the settlement areas during dispersal (Ferrer and Penteriani 2008, Penteriani et al. 2006b, Penteriani et al. 2008).

In many cases, studies of population ecology have failed to consider the importance of floaters. In fact, nonbreeding individuals have frequently been considered a numeric entity without identity, whose primary features are their immigration rates (e.g., Tamarin 1978, Lomnicki 1988, Remmert 1994, Sutherland 1996), without any consideration of spatiotemporal contact with the population from which they originated (e.g., Clobert et al. 2001, Bullock et al. 2002). But it is crucial to bear in mind that animal populations are an indivisible mix of breeders and floaters, with dispersal being one of the main 
factors determining population structure, dynamics and stability (Forsman et al. 2002).

However, floaters and their dynamics in settlement areas are not the only factors that we should consider when studying dispersal in raptor populations. The effect of dispersing predators can extend beyond their role as future breeders. Depending on when they move and stop during dispersal, they can also negatively interact with those raptor communities that overlap in space with dispersers (i.e., intraguild predation between dispersing individuals and their intraguild prey). Generally, the effects of intraguild predation have been evaluated in the breeding sectors of both intraguild predator and prey breeding populations (e.g., Sergio et al. 2003). However, the effect of the presence of a top predator on raptor communities can be underestimated when considering breeding birds only (e.g., when evaluating the rates of intraguild predation by studying the diet of breeding pairs only). Actually, intraguild predation may also occur within the settlement areas chosen by dispersing individuals of intraguild predators, when they represent the breeding areas of potential intraguild prey. Also, because floating individuals may settle close to breeding pairs of intraguild predators, the effects of the intraguild predator on its intraguild prey may be underestimated because we have not monitored the diet of these "invisible" floaters. In fact, in some species such as the large Great Horned Owl (Bubo virginianus) and its European ecological counterpart, the Eurasian Eagle-Owl (Bubo bubo), several floaters may share the home range of their conspecific breeders and be almost undetectable due to their furtive behaviors (avoidance of risky aggression by territorial conspecifics; Rohner 1997).

The Complexity of Dispersal as a Multistep Process. Although dispersal has been frequently represented and/or described as fixed process, recent information has illustrated the complexity of this multistep process. In actuality, dispersal can be subdivided into three sequential, but distinct, phases (e.g., Andreassen et al. 2002, Bowler and Benton 2005): (1) Start, when an individual leaves its place of birth; (2) Wandering, when the dispersing individual searches for new areas before temporary settlement; and (3) Stop, when the individual settles in a temporary settlement area, defined as a region occupied for a fairly long period of time relative to the entire dispersal process, or until it becomes an owner of a breeding territory (Fig. 1A). One of the most important consequences of the multistep process of dispersal is that individuals can shift among different behaviors and strategies depending on the stage in which they are (Bowler and Benton 2005, Delgado and Penteriani 2008; Fig. 1B-1E). Such differences in individual dispersal strategies can engender important consequences in relation to: (a) proximate factors, such as the individual responses to conspecifics and the configuration of spatial trajectories (see also Van Dyck and Baguette 2005); and (b) the intrinsic properties of the whole population resulting from the individual dynamics and fates relative to dispersal. The shifts among behaviors may correspond to the ability of individuals to respond to their experiences with conspecifics and in various habitats as they move (Dall et al. 2005). All these possible variations were rarely considered in empirical studies and there are particularly few data on behaviors during the different phases. The different strategies employed during the search for settlement areas will affect the final destiny of dispersing individuals and, consequently, that of their natal population and/or the population in which they will settle. Because dispersal-movement behavior has important consequences in raptor population, community, and ecosystem composition and functioning, raptor ecologists need to identify factors that most affect the movement of animals when floating in search of stable settlement areas and breeding territories.

When studying dispersal, researchers should bear in mind that dispersal is essentially the result of movements associated with both daily needs (i.e., routine movements) and also longer-distance movements to search for a suitable habitat for successful temporary settlement or breeding (Van Dyck and Baguette 2005). Moreover, from an adaptative perspective, individuals should adjust their movement behavior as a response to variations in external conditions. Because causes, consequences, costs, and benefits of dispersal can vary not only among species but also among individuals, a flexible dispersal strategy is advantageous (Delgado and Penteriani 2008). It is interesting to study behavioral decisions during the different steps of dispersal because it gives insight into factors that influence dispersal patterns and population dynamics. The general patterns we observe in the dispersal of tagged birds can hide precious and unexpected information, which may be discovered when we examine dispersal in terms of individual behaviors and strategies (Fig. 1).

Individual characteristics may shape dispersal behavior. For example, Baguette and Van Dyck (2007) 

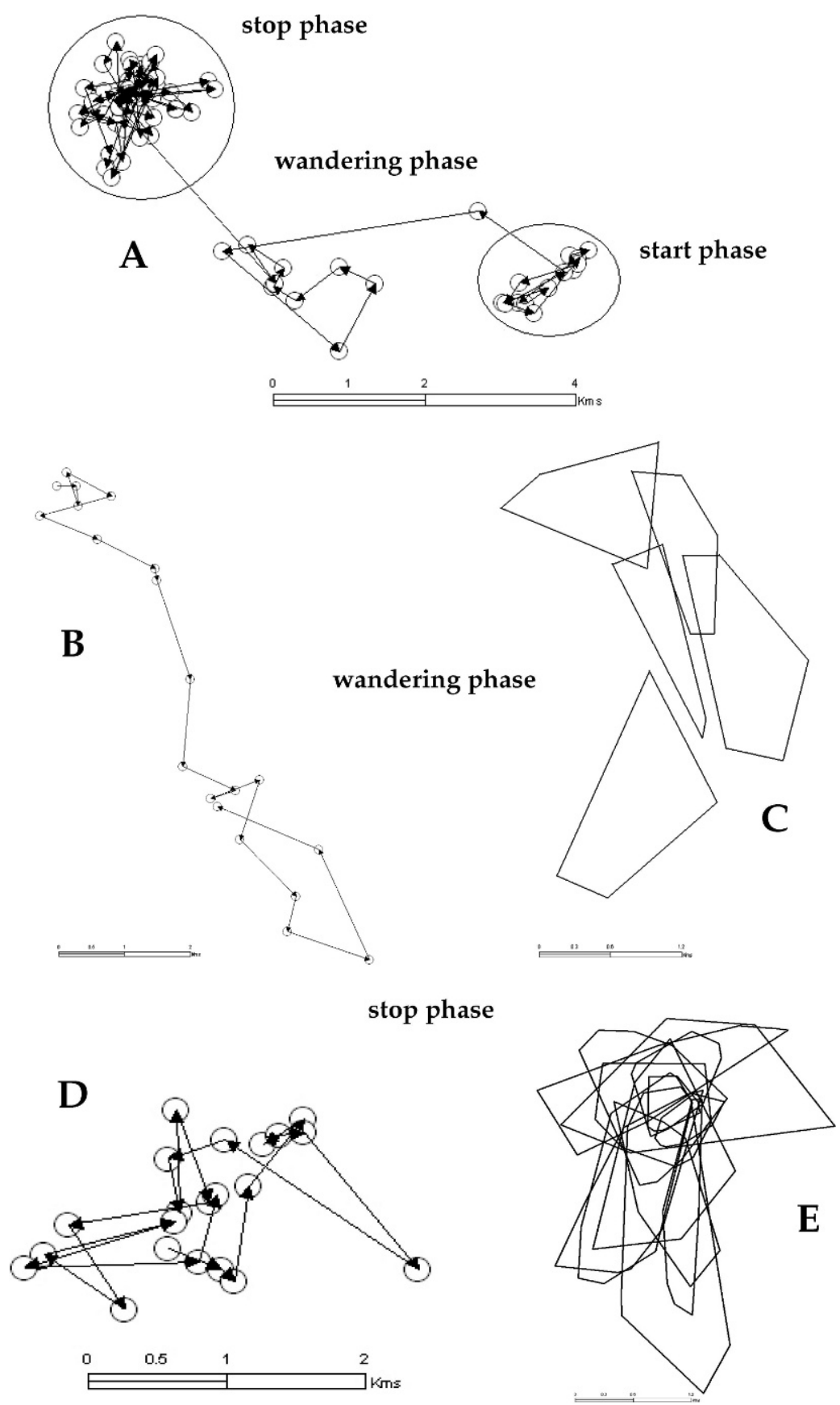

Figure 1. General patterns of natal dispersal may obscure unexpected and interesting information, which may be detected by examination of individual strategies and behaviors in natal dispersal. For example, for a Eurasian Eagle-Owl (Bubo bubo) juvenile in southern Spain (Fig. 1A), movement behaviors and strategies associated with space use are not the same during the different phases of dispersal (see text for more details on the stages of the dispersal process). During the wandering phase, individuals generally move over long distances (Fig. 1B represents owl movements during one night) and rarely frequent the same area (Fig. 1C shows the different ranges occupied by the same owl during different, consecutive nights). On the contrary, during the stop phase (when floaters inhabit quite stable settlement areas), nightly movements are shorter (Fig. 1D), and spatial overlaps seem to delimitate a quite well-defined "home range" (Fig. 1E). 
highlighted a "shyness-boldness" dichotomy in individual behaviors, in which bold animals were the most aggressive and most able to make rapid decisions, whereas shy individuals acted with more caution and were more adaptable to external situations. These individual traits may have an influence on patterns of dispersal in populations, with bolder individuals dispersing further than shyer ones (Fraser et al. 2001, Dingemanse et al. 2003, Delgado and Penteriani 2008). This may mean that the fate of dispersing individuals is not fixed but variable, with each population showing different patterns of dispersal behavior as a function of the characteristics of its individuals.

Dispersal from the Perspective of Animal Movement. Patterns of animal movement provide a mechanism for understanding important aspects of ecology, as they influence complex patterns of population spatial structure (see review in Delgado and Penteriani 2008). The analyses of movement patterns have helped to clarify dispersal causes and consequences (Clobert et al. 2001), spatial and temporal variations of dispersal costs and benefits (Denno et al. 1989, Waser et al. 1994), as well as beneficial and detrimental effects of individual displacements on the persistence of spatially structured systems (Hanski 1999, Heino et al. 1997).

However, although several empirical studies support some of the most typical models of animal dispersal, such data generally are derived from experimental studies or data on short-term movements of invertebrate species. These data likely show less complexity and variability than dispersal of vertebrates moving through a heterogeneous and complex natural world. Individuals searching suitable habitat patches while dispersing will be influenced by several biotic and abiotic factors, which will generate different dispersal strategies among individuals and species under different conditions and life stages of dispersal. These factors act together with animal cognitive abilities (With and Crist 1995, With et al. 1997, 1999) and learning capabilities (Stamps and Krishnan 1999, Saarenmaa et al. 1988, Vuilleumier and Perrin 2006). To date, however, there has been little empirical exploration of the complex effects of biotic and abiotic factors on animal movements under natural conditions. We encourage future studies on raptors to include the study of animal movements. In fact, the analysis of movement patterns can be easily derived from data collected passively during radiotracking of dispersing individuals, without additional costs or efforts, and such analyses can reveal unexpected features, patterns and trends of the dispersal process.

Routes of Natal Dispersal, and Ideal Free vs. Despotic Distributions of Individuals in Space. Although spatial connectivity has been recognized as a fundamental element affecting the success of dispersing individuals, it has been seldom considered in raptor research. Many dispersal patterns follow a dispersal flow that is polarized along both a specific axis and direction (Gustafson and Gardner 1996, Ferreras 2001), which is indicative of asymmetric dispersal (see Kauffman et al. 2004 for an empirical case and Vuilleumier and Possingham 2006 for a review on factors determining asymmetric dispersal), and has several important consequences on populations and source-sink dynamics.

Because the number of connected patches largely determines population viability in an asymmetric system (Vuilleumier and Possingham 2006), we may expect a population decline if the most frequented patches connecting breeding territories to settlement areas disappear or are affected by environmental stochasticity. Exact knowledge of the settlement areas and dispersal routes may provide opportunities for species conservation and landscape management; however, a broad-spectrum increase of connectivity is unlikely to benefit populations characterized by asymmetric dispersal. As shown by Walls and Kenward (1998) and Forsman et al. (2002), for species needing recovery plans, an accurate knowledge of dispersal behavior can be a crucial factor for conservation success, as efficient reintroduction/restocking requires accurate knowledge of the animals' movement patterns. Moreover, individuals may prefer to settle in habitats similar to their natal habitats, because (a) this behavior reduces the costs of assessing suitable new habitats, or (b) experience in natal habitat improves performance if an animal settles in the same habitat type after dispersing (Stamps 2001). This kind of information is urgently needed for most species of raptors, particularly those that are the focus of conservation efforts.

Because dispersers seem to move with no apparent constraints limiting their spatial explorations (i.e., with a free mobility that will distribute them ideally so as to maximize fitness), they should follow an ideal free distribution (IFD; Fretwell and Lucas 1970). In fact, during dispersal, raptors are not territorial and may homogeneously distribute themselves in space, with the distribution of local resources being the only apparent constraints to 
movements and settlements. However, detailed analysis of dispersal patterns may reveal that the distribution of individuals may be under constraints other than territoriality or location of food resources (e.g., asymmetric dispersal), resulting in a quasidespotic spatial distribution. Once again, raptors may be interesting species for theoretical studies and modeling, mainly due to their unusual life histories.

Conservation Implication of Dispersal. Recently, projections of population trajectories into the future have attracted much attention from scientists, decision-makers, and the general public. Habitat loss and human interference with natural processes, as well as occurrence of natural stochastic events, may increase species' vulnerability and influence population dynamics (Pimm et al. 1995, Owens and Bennett 2000, Woodruff 2001, Baguette et al. 2003, Balbontín et al. 2005, Schtickzelle et al. 2006, 2007).

Predictive models of population trends should include variables for both deterministic and stochastic factors (Woodroffe and Ginsberg 1998, Schtickzelle et al. 2006), and should consider the whole population (e.g., breeders and floaters). To create such models, we must understand how and why populations fluctuate or remain stable and also the factors that contribute to such population patterns. In most published studies, the primary ecological attributes that have been linked to the probability of a species (or population) extinction include various biological parameters of only the breeding population (e.g., McKelvey 1996, Brook et al. 2000, Purvis et al. 2000, Rodrigues et al. 2000, Sæther et al. 2000, Donald and Greenwood 2001). The dynamics of nonbreeders, as well as the temporary settling zones used during dispersal have been poorly studied. Thus, the effects of habitat quality and loss in settlement areas, mortality rates of nonbreeders, and environmental stochasticity have been only rarely considered in such models.

Long-lived species, such as raptors, are usually more sensitive to human persecution and small perturbations than are species with short life spans (Bennett and Owens 1997, Beissinger 2000, Owens and Bennett 2000). Field studies on raptors have frequently illustrated that the areas in which floaters settle temporarily may be very different from their eventual breeding areas (e.g., Ferrer 1993, Ferrer and Harte 1997, Delgado and Penteriani 2005), and such settlement areas can be areas with great human disturbance that would not be included in typical management plans (Ferrer 1993, Delgado and Penteriani 2005). Therefore, potential future breeders of populations may spend a large part of their lives (the period from the beginning of dispersal to the first reproduction) in high-risk areas. In fact, stochastic events, such as human persecution or collisions with power lines or vehicles, can seriously increase mortality rates in the temporary settlement areas. Because the areas where dispersers settle are unknown or difficult to detect, little effort is devoted to the conservation of these sites compared with breeding territories, which can result in less-effective conservation plans and action. Because conservation efforts for endangered species and/or populations focus primarily on breeding areas, conservation programs conducted in breeding territories can be ineffective if the genuine problem is in the settlement areas. In fact, declines in breeding population size may divert our attention from the real problem, e.g., by eliciting increased conservation in breeding areas although limiting factors actually are acting in settlement areas or dispersal routes. As a consequence, focusing conservation efforts on dispersal areas of a population may have important socio-economic repercussions for: (a) establishing protected areas; (b) preparing conservation plans for endangered species; and (c) building predictive models of species distribution.

Finally, because raptors seem to be reliable indicators of areas of high biodiversity (Sergio et al. 2005, 2006, 2008; but see also Cabeza et al. 2008, Kéry et al. 2008, Roth and Weber 2008), dispersing individuals may reveal the locations of unexpected but crucial areas of conservation interest, i.e., the settlement areas where they stop during dispersal.

To conclude, raptors represent extremely interesting species because of the characteristics of their life histories and the paucity of ecological data on this group of species. Recent studies on raptors have demonstrated that novel approaches to fieldwork can overcome the inherent difficulties of working with them. Despite the challenges of raptor research, we encourage researchers to devote more attention to the subject of raptor dispersal within a broad ecological perspective. This will allow us to broaden the field of raptor research and not limit it to a species-specific approach.

\section{ACKNOWLEDGMENTS}

We thank M. Ferrer and V.O. Nams for stimulating discussion on dispersal, and M. Thornton for the critical review of the first draft of the manuscript. 


\section{Literature Cited}

Andreassen, H.P., N.C. Stenseth, And R.A. Ims. 2002. Dispersal behaviour and population dynamics of vertebrates. Pages 237-256 in J.M. Bullock, R.E. Kenward, and R.S. Hails [EDS.], Dispersal ecology. Blackwell Publishing, Oxford, U.K.

Baguette, M., G. Mennechez, S. Petit, and N. SchtickZELLE. 2003. Effect of habitat fragmentation on dispersal in the butterfly Proclossiana eunomia. C. R. Biol. 326:S200-S209.

— AND H. VAN DYCK. 2007. Landscape connectivity and animal behavior: functional grain as a key determinant for dispersal. Landsc. Ecol. 22:1117-1129.

Balbontín, J., V. Penteriani, And M. Ferrer. 2005. Humans act against the natural process of breeder selection: a modern sickness for animal populations? Biodivers. Conserv. 14:179-186.

Beissinger, S.R. 2000. Ecological mechanisms of extinction. Proc. Natl. Acad. Sci. U.S.A. 97:11688-11689.

BennetT, P.M. AND I.P.F. Owens. 1997. Variation in extinction risk among birds: chance or evolutionary predisposition? Proc. R. Soc. Lond. B Biol. Sci. 264:401-408.

Bowler, D.E. And T.G. Benton. 2005. Causes and consequences of animal dispersal strategies: relating individual behaviour to spatial dynamics. Biol. Rev. 80:205225.

Brook, B.W., J.J O'Grady, A.P. Chapman, M.A. Burgman, H.R. Aкçakaya, and R. Frankham. 2000. Predictive accuracy of population viability analysis in conservation biology. Nature 404:385-387.

Bullock, J.M., R.E. Kenward, AND R.S. HaILs. 2002. Dispersal ecology. Blackwell Publishing, Oxford, U.K.

Cabeza, M., A. Arponen, And A. Van Teeffelen. 2008. Top predators: hot or not? A call for systematic assessment of biodiversity surrogates. J. Appl. Ecol. 45:976-980.

Clobert, J., E. Danchin, A.A. Dhondt, And J.D. Nichols. 2001. Dispersal. Oxford University Press, Oxford, U.K.

Dall, S.R.X., L.-A. Giraldeau, O. Olsson, J.M. McNamara, AND D.W. STEPhens. 2005. Information and its use by animals in evolutionary ecology. Trends Ecol. Evol. 20:187-193.

Delgado, M.M. and V. Penteriani. 2005. Eagle owl Bubo bubo dispersal patterns and the importance of floaters for the stability of breeding populations. Ornithol. Anz. 44:153-158.

- AND —. 2008. Behavioral states help translate dispersal movements into the spatial distribution patterns of floaters. Am. Nat. 172:475-485.

Denno, R.F., K.L. Olmstead, and E.S. McCloud. 1989. Reproductive cost of flight capability: a comparison of life history traits in wing dimorphic planthoppers. Ecol. Entomol. 14:31-44.

Dingemanse, N.J., C. Both, A.J. Van Noordwijk, A.L. RutTEN, AND P.J. DRENT. 2003. Natal dispersal and personalities in Great Tits (Parus major). Proc. R. Soc. Lond. B Biol. Sci. 270:741-747.
DONALD, P.F. AND J.J.D. GREENWOOD. 2001. Spatial patterns of range contraction in British breeding birds. Ibis 143:593-601.

FERRER, M. 1993. Juvenile dispersal behaviour and natal philopatry of a long-lived raptor, the Spanish Imperial Eagle Aquila adalberti. Ibis 135:132-138.

— AND M. HARTE. 1997. Habitat selection by immature Spanish Imperial Eagles during the dispersal period. J. Appl. Ecol. 34:1359-1364.

- AND V. PENTERIANI. 2008. Non-independence of demographic parameters: positive density-dependent fecundity in eagles. J. Appl. Ecol. 45:1453-1459.

FERrERAS, P. 2001. Landscape structure and asymmetrical inter-patch connectivity in a metapopulation of the endangered Iberian lynx. Biol. Conserv. 100:125-136.

Forero, M.G., J.A. DonÁZAR, AND F. Hiraldo. 2002. Causes and fitness consequences of natal dispersal in a population of Black Kites. Ecology 83:858-872.

Forsman, E.D., G.A. Robert, J.A. ReId, P.J. Loschl, S.G. SoVern, M. TAYlor, B.L. Biswell, A. Ellingson, E.C. MESlow, G.S. Miller, K.A. Swindle, J.A. Thrailkill, F.F. WAGNER, AND D.E. SEAman. 2002. Natal and breeding dispersal of Northern Spotted Owls. Wildl. Monogr. 149:1-35.

Fraser, D.F., J.F. Gilliam, M.J. Daley, A.N. Le, And G.T. SKALSKI. 2001. Explaining leptokurtic movement distributions: intrapopulation variation in boldness and exploration. Am. Nat. 158:124-135.

FreTwELL, S.D. AND H.L. LuCAS. 1970. On territorial behaviour and other factors influencing habitat distribution in birds. I. Theoretical development. Acta Biotheor. 19:16-36.

Greenwood, P.J. 1980. Mating systems, philopatry and dispersal in birds and mammals. Anim. Behav. 28:11401162.

Gustafson, E.J. And R.H. Gardner. 1996. The effect of landscape heterogeneity on the probability of patch colonization. Ecology 77:94-107.

HANSKI, I. 1999. Metapopulation ecology. Oxford University Press, Oxford, U.K.

AND O.E. GaGgiotTi. 2004. Ecology, genetics, and evolution of metapopulations. Elsevier Academic Press, London, U.K.

Heino, M., V. Kaitala, E. Ranta, and J. Lindström. 1997. Synchronous dynamics and rates of extinction in spatially structured populations. Proc. R. Soc. Lond. B Biol. Sci. 264:481-486.

Kauffman, M.J., J.F. Pollock, And B. Walton. 2004. Spatial structure, dispersal, and management of a recovering raptor population. Am. Nat. 164:582-597.

KeNWARD, R.E., S.S. WALLS, AND K.H. HODDER. 2001. Life path analysis: scaling indicates priming effects of social and habitat factors on dispersal distances. J. Anim. Ecol. 70:1-13.

KéRY, M., J.A. RoYLe, AND H. SCHMID. 2008. Importance of sampling design and analysis in animal population studies: a comment on Sergio et al. J. Appl. Ecol. 45:981986. 
KoOpman, M.E., G.D. Hayward, AND D.B. MCDOnAld. 2007. High connectivity and minimal genetic structure among North American Boreal Owl (Aegolius funereus) populations, regardless of habitat matrix. Auk 124:690704.

LOMNICKI, A. 1988. Population ecology of individuals. Princeton University Press, Princeton, NJ U.S.A.

McKelvey, R. 1996. Viability analysis of endangered species: a decision-theoretic perspective. Ecol. Model. 92:193-207.

Owens, I.P.F. AND P.M. BenNeTt. 2000. Ecological basis of extinction risk in birds: habitat loss versus human persecution and introduced predators. Proc. Natl. Acad. Sci. U.S.A. 97:12144-12148.

Penteriani, V., M.A. Fortuna, C.J. Melián, F. Otalora, AND M. FERRER. 2006a. Can prey behaviour induce spatially synchronic aggregation of solitary predators? $\mathrm{O} i$ kos 113:497-505.

, F. OtAlora, AND M. FerRer. 2005a. Floater survival affects population persistence. The role of prey availability and environmental stochasticity. Oikos 108:523534.

$\longrightarrow,-$ AND $\longrightarrow$ 2006b. Floater dynamics can explain positive patterns of density-dependence fecundity in animal populations. Am. Nat. 168:697-703.

,$- \longrightarrow$, AND $\longrightarrow$ 2008. Floater mortality within settlement areas can explain the Allee effect in breeding populations. Ecol. Model. 213:98-104. , F. Sergio, ANd M. Ferrer. 2005b. Environmental stochasticity in dispersal areas can explain the "mysterious" disappearance of breeding populations. Proc. R. Soc. Lond. B Biol. Sci. 272:1265-1269.

Pimm, S.L., G.J. Russell, J.L. Gittleman, And T.M. Brooks. 1995. The future of biodiversity. Science 269:347-350.

Purvis, A., J.L. Gittleman, G. Cowlishaw, and G.M. Mace. 2000. Predicting extinction risk in declining species. Proc. R. Soc. Lond. B Biol. Sci. 267:1947-1952.

Remmert, H. 1994. Minimum animal populations. Springer-Verlag, Berlin, Germany.

Rodrigues, A.S.L., R.D. Gregory, AND K.J. GASTON. 2000. Robustness of reserve selection procedures under temporal species turnover. Proc. R. Soc. Lond. B Biol. Sci. 267:49-55.

Rohner, C. 1997. Non-territorial 'floaters' in Great Horned Owls: space use during a cyclic peak of snowshoe hares. Anim. Behav. 53:901-912.

Ronce, O. 2007. How does it feel to be like a rolling stone? Ten questions about dispersal evolution. Annu. Rev. Ecol. Evol. Syst. 38:231-253.

Roth, T. AND D. WEBER. 2008. Top predators as indicators for species richness? Prey species are just as useful. $J$. Appl. Ecol. 45:987-991.

SaArenmaa, H., N.D. Stone, L.J. Folse, J.M. Packard, W.E. Grant, M.E. Makela, and R.N. Coulson. 1988. An artificial intelligence modeling approach to simulating animal/habitat interaction. Ecol. Model. 44:125141.
SÆCther, B.-E., S. EngEn, R. LAnde, P. ArCese, AND J.N.M. SMITH. 2000. Estimating the time to extinction in an island population of Song Sparrows. Proc. R. Soc. Lond. B Biol. Sci. 267:621-626.

Schtickzelle, N., A. Joiris, H. Van Dyck, and M. Baguette. 2007. Quantitative analysis of changes in movement behaviour within and outside habitat in a specialist butterfly. BMC Evol. Biol. 7:4.

, G. Mennechez, and M. Baguette. 2006. Dispersal depression with habitat fragmentation in the bog fritillary butterfly. Ecology 87:1057-1065.

Serrano, D. and J.L. Tella. 2003. Dispersal within a spatially structured population of Lesser Kestrels: the role of spatial isolation and conspecific attraction. J. Anim. Ecol. 72:400-410.

- - - J.A. DonÁZAR, ANd M. Pomarol. 2003. Social and individual features affecting natal dispersal in the colonial Lesser Kestrel. Ecology 84:3044-3054.

Sergio, F., L. Marchesi, And P. Pedrini. 2003. Spatial refugia and the coexistence of a diurnal raptor with its intraguild owl predator. J. Anim. Ecol. 72:232-245.

- I. NewTON, AND L. MARChESI. 2005. Top predators and biodiversity. Nature 436:192.

- - , AND — 2008. Top predators and biodiversity: much debate, few data. J. Appl. Ecol. 45:992999.

$\longrightarrow,-\longrightarrow$, AND P. PEDRINI. 2006. Ecologically justified charisma: preservation of top predators delivers biodiversity conservation. J. Appl. Ecol. 43:1049-1055.

STAMPS, J.A. 2001. Habitat selection by dispersers: integrating proximate and ultimate approaches. Pages 230-242 in J. Clobert, E. Danchin, A.A. Dhondt, and J.D. Nichols [EDs.], Dispersal. Oxford University Press, New York, NY U.S.A.

— AND V.V. KRISHNAN. 1999. A learning-based model of territory establishment. Q. Rev. Biol. 74:291-318.

SutherLand, W.J. 1996. From individual behaviour to population ecology. Oxford University Press, Oxford, U.K.

TAMARIN, R.H. 1978. Population regulation. Hutchinson and Ross, Stroudsburg, PA U.S.A.

VAn Dyck, H. And M. BaguetTe. 2005. Dispersal behaviour in fragmented landscapes: routine or special movements? Basic Appl. Ecol. 6:535-545.

Vuilleumier, S. ANd N. Perrin. 2006. Effects of cognitive abilities on metapopulation connectivity. Oikos 113: 139-147.

__ And H.P. Possingham. 2006. Does colonisation asymmetry matter in metapopulations? Proc. R. Soc. Lond. B Biol. Sci. 273:1637-1642.

WASER, R.F., S.R. Creel, AND J.R. LuCAS. 1994. Death and disappearance, estimating mortality risk associated with philopatry and dispersal. Behav. Ecol. 5:135-141.

WALls, S.S. AND R.E. KenWARD. 1998. Movements of radiotagged buzzards Buteo buteo in early life. Ibis 140:561-568.

,-- aNd G.J. Holloway. 2005. Weather to disperse? Evidence that climatic conditions influence vertebrate dispersal. J. Anim. Ecol. 74:190-197. 
Wiens, A.J. 2001. The landscape context of dispersal. Pages 96-109 in J. Clobert, E. Danchin, A.A. Dhondt, and J.D. Nichols [EDS.], Dispersal. Oxford University Press, New York, NY U.S.A.

With, K.A., S.J. Cadaret, And C. Davis. 1999. Movement responses to patch structure in experimental fractal landscapes. Ecology 80:1019-1030.

- AND T.O. CRIST. 1995. Critical thresholds in species' responses to landscape structure. Ecology 76:24462459 .
, R.H. GARDNER, AND M.G. TURNER. 1997. Landscape connectivity and population distributions in heterogeneous environments. Oikos 78:151-169.

WoOdroffe, R. AND J.R. GINSBERG. 1998. Edge effects and the extinction of populations inside protected areas. Science 280:2126-2128.

WoODRuFF, D.S. 2001. Declines of biomes and biotas and the future of evolution. Proc. Natl. Acad. Sci. U.S.A. 98:5471-5476.

Received 2 June 2008; accepted 20 January 2009 